the vagina, or to perform abdominal section with a view either to suprapubic drainage if a simple abscess had been found, or removal of the tumour if it should prove a suppurating ovary or tube. The first course was abandoned on the grounds not only of the extreme mechanical difficulty of keeping any tube inserted through the rectum in position, but also from the uncertainty of diagnosis, for if the swelling should prove to be a cyst ultimately requiring removal, it was of great importance if possible to get the rectal opening closed. Of the two remaining alternatives; drainage by the vagina was selected for the following reasons: (1) That the swelling could be felt projecting prominently into the vagina, whereas, being so deeply situated, it could not be felt above the pubes. (2). That if the swelling should prove to be a suppurating eyst, it would be a great advantage to allow time for the recto-cystic fistula to spontaneously close, which we thought might be accomplished by temporary drainage. This hypothesis fortunately proved correct, for no sooner was the vaginal drainage established than the pus ceased to be discharged by the rectum, and when abdominal section was performed some weeks later the opening was found completely closed. The risk to the patient's life when the operation was performed was doubtless considerably less than if the rectal opening had still existed, for it was so low down that its effectual closure would have been extremely doubtful.

It is open to discussion whether in a similar case temporary drainage might not be better and more safely established by abdominal section. The propriety of such a procedure would probably be determined by the situation of the swelling. In our case it would have been very difficult to have got at the cavity from above, and if it had proved to have been an abscess, it would have been nearly impracticable to have fixed the edges of the opening to the parietal peritoneum, and anything short of this would have been highly dangerous, from the nature of the pus. On the other hand the abscess was almost pointing into the vagina. If the tumour had been situated high - up in the pelvis, primary abdominal section with a view to removal or drainage would probably have been the right course.

The remaining cases recorded were simpler in their nature, inasmuch as the diagnosis was clear. There was no doubt that the tumours were suppurating cysts and not simple abscesses, and from the fact that no opening could be felt within 4 inches of the anus, there seemed a fair chance of the fistulæ being sufficiently high for effectual closure after removal of the tumour. In two of the cases the openings were found in an accessible position and accurately closed by suture; but unfortunately in Case Iv the position of the hole right behind the rectum made its accurate closure impracticable.

As regards the details of the proceedure in the circumstances of this case, in which there was no guarantee that the opening into the rectum was effectually closed by suture, there may be some difference of opinion. The tumour, owing to the way in which it had extended beneath the broad ligament was practically extraperitoneal, and had it been possible the edges of the opening in the broad ligament through which it had been shelled out should have been raised and stitched to the lower angle of the abdominal incision, and drained. The only other feasible plan other than that which was adopted would have been to have entirely closed the opening in the broad ligament in situ, trusting that the cavity would have drained through the hole in the rectum, and eventually have closed up.

After carefully considering the facts in the case recorded, should I have the misfortune again to meet with a similar condition, I would, in the event of its being impracticable to raise the edges of the open broad ligament to the lower angle of the abdominal wound, prefer completely to close the broad ligament in situ, and trust to rectal drainage rather than run the risk of suprapubic drainage through the peritoneum.

Porsoning BY Misadventure.-It is understood that at a moting of the Law Committee of Edinburgh 'Town Council, on January 17th, the mother of the young woman Swan, who was accidentally poisoned at the Fever Hospital some weeks ago, intimated her acceptance of $£ 100$ in satisfaction of her claim for damages, together with $£ 25$ for expenses.

\section{ACUTE YELLOW ATROPHY OF THE LIVER.}

BY ALEXANDER McPHEDRAN, M.B.,

Lecturer on Clinical Medicine in the University of Toronto; AND

A. B. MACalluM, M.B., Ph.D. (Johns Hopkins), Lecturer on Physiology in the University of Toronto.

CASES of acute yellow atrophy are so rarely met with, that it seems desirable to give as full and explicit a report of the following one as the circumstances will admit of. Unfortunately, at the time the patient entered the hospital the burden of 'work was so excessive, on account of the epidemic of influenza then prevailing, that it was impossible to give the case the attention which it merited.

E. V., aged 24, admitted to the Toronto General Hospital, under Dr. McPhedran, January 31st, 1890.

History.-A domestic servant, unmarried. In infancy she had a slight attack of infantile paralysis, from which resulted some talipes varus of the right foot, since then she has been healthy. Her father, a brother, nothing of note. Her present illness began about January 1st with a cold nothing of note. Her present illness began about January lst with a cold
from exposure. Two or three days later she took influenza, and the skin was noticed to be yellowish. She had some attacks of free epistaxis. She gradually grew worse, the jaundice deepening, and the stools She gradually grew worse, the jaundice deepening, and the stools becoming slate coloured and offensive, soon acquiring a clay colour: cious, but that was attributed to pregnancy, which was supposed to be of about five months' duration. There was occasional vomiting of her food, with some slightly bile-stained mucus. Her mental condition was clear till near the end of January, when she began to grow apathetic and dull
of comprehension. She continued to work until after the middle of the month.

Present Condition.-She is very deeply jaundiced, fairly nourished, evidently between five and six months pregnant. The only answer that can be gotten to any question is "the last three weeks." Her pupils are small but active. There is some brownish, sticky mucus adhering to the lips and teeth. She lies quietly, taking notice of nothing:takes liquid nourishment when offered. Temperature in the axilla. 97.4 ${ }^{\circ} \mathrm{F}$., pulse 76. The abdomen is somewhat distended and tympanitic, except over the pregnant uterus. The area of hepatic dulness terminates an inch above the margin of the ribs; seems tender to pressure. over it, and to pressure upward under the ribs. Area of splenic dulness. extends to margin of ribs. Heart and lungs present nothing abnormal. Urine normal in quantity, dark, acid, specific gravity 1023. Tests: readily give evidence of presence of bile pigments. Quantity of urea. tyrosin are easily found; bowels constipated; considerable nausea, with tyrosin are easily found; bowels
vomiting of bile-stained mucus.

Fobruary 1st. The hebetude has deepened to semi-coma, with muttering February 1st. The hebetude has deepened to semi-coma, with muttering
delirium. She vomits everything that is given, also much dark, grumoug. delirium. She vomits everything that is given, also much dark, grum
fluid. The pulse continues slow, and the temperature subnormal.

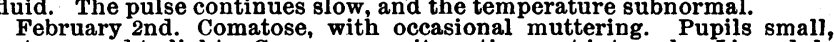
February 2 d. Comatose, with occasional muttering. Pupils small, but respond to light. Grumous vomit continues

ness still further diminished. She died at 9 P M. mortis well marked. General surface and mucous membranes deeply jaundiced. Pupils dilated. No cutaneous hæmorrhages. Pericardium bile stained, and contains one ounce of-bile-stained serum. Endocardium bile-stained, also ante-mortem clot in right ventricle. Condition of muscles not noted. Pleuræ numerous hæmorrhagic patches in right; recent adhesions in left. Lungs deeply congested. Peritoneum bilestained. Spleen large and soft. Kidneys: capsule slightly adherent; cortex enlarged. Liver had receded under ribs; weighed 25 ounces; very flaccid, rather than friable; mostly red, but with some yellow patches; surface wrinkled. Gall bladder not noted. Stomach distended with gas, and contained much grumous fluid. Intestines contained much flatus; hardened fæces in colon. Uterus contained a five-month foetus, which had been dead some days. Unfortunately, the patholog.
conducted the necropsy only preserved the liver for examination.

\section{Pathologicat Histologì.}

A small piece only of the liver came for examination, and from what lobe this was taken could not be ascertained. It was hardened in alcohol, whereby the fixation was so complete that even the minute details of karyokinesis are readily and clearly seen in the hepatic cells. A part of the piece was stained in toto with hæmatoxylin and eosin, embedded, by means of the chloroform process, in paraffin, and sectioned to the thickness of $10 \mu$ and under. These sections were fastened to the slide by means of the clove-oil-collodion mixture, and mounted in the usual way in benzole-balsam. We rere forced to adopt the cementing of the sections to the slide, since without this the removal of the paraffin entails loss of many of the important elements necessary to determine the extent of the change in the tissue.

We had no opportunity of examining microscopically the liver in the fresh state, but this, we think, is a matter of regret only as regards the pigments of the areas affected with red atropliy, which have been removed, apparently, from the tissue by the alcohol. 
So extensive here is the condition known as red atrophy that one of the authors at first concluded that the sections exemplified this condition alone. Fully nine-tenths of each section show no trace of hepatic cells at all, and these are present mainly directly under the capsule (Fig. 1). The

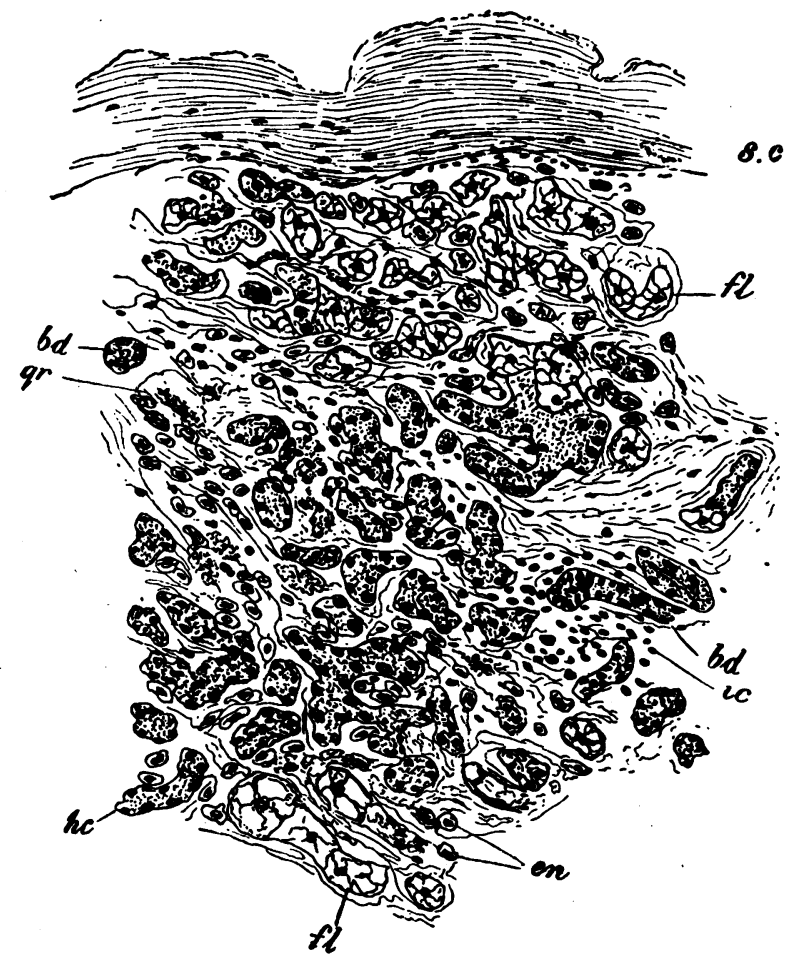

Fig. 1.-Represents a portion of the yellow area immediately under the serosa. In this part there was inflammatory infiltration, an occurrence not usual in the sections; $8 c$, serous covering; $h c$ hepatic cells; $f l$, liver cells distended with fat globules; $b d$, bile duct; en endothelial cells; $i c$, inflammatory cells; $g r$, granular duct; en, endothelial cells ; $i$ c, inflammatory cells; ;

outlines of the original lobules can be made out roughly by the distribution of the biliary ducts, which are very abundant here-so much so that in the smaller interlobular canals as many as twelve and more have been often counted. The circulation of the blood in these lobules must have been greatly impeded during the progress of the disease, since in the great majority of cases all traces of venulæ centrales have disappeared.

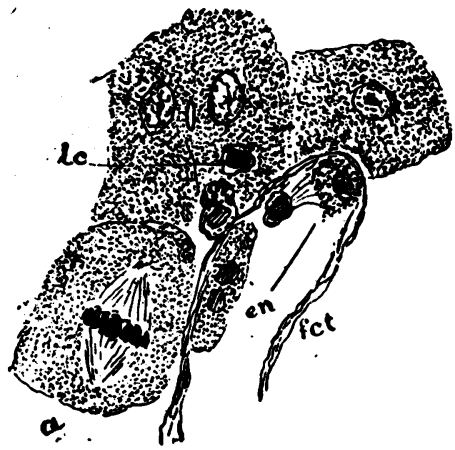

Fig. 2.-A group of nearly normal hepatic cells with a blood capillary, from the yellow area; $a$, hepatic cell with nucleus in the process of division; $e n$, endothelial cells, enlarged; $f$ ct, fibrillar connective tissue in the vascular wall; $l c$, leucocytes in the interior of a liver cell. $\times 1,000$.

Frequently in the lobules so roughly outlined in the sections small bile ducts can be seen, and sometimes these are continuous with those at the margin of the lobules. The origin of these, as well as of some of the interlobular ones, has been variously interpreted. Waldezer, Zenker, Winiwarter, and others regard them as derived from the original bile ducts by proliferation of their cells, and consider that a regeneration of the hepatic parench yma obtains through this process; while Klebs and Perls believe that the atrophying fiver cells arrange themselves in rows which simulate bile ducts. Apparently Dreschfeld holds that a combination of both views is the true explanation.

We cannot subscribe to any one of these views; for, if the cells of the bile ducts multiply by division, some evidence of this ought to be present in our preparations. Not one single case of karyokinesis was observed in the great number of ducts examined, and this could not be due to faulty methods of treatment, since the same sections readily show a number of hepatic cells in division. On the other hand, it is scarcely possible that atrophy of a lobule would proceed so far as to leave only two or three parallel rows of cells, which, approximating, would form the ducts in question. Why should degeneration and death overtake all the other hepatic cells and leave only parallel rows here and there?

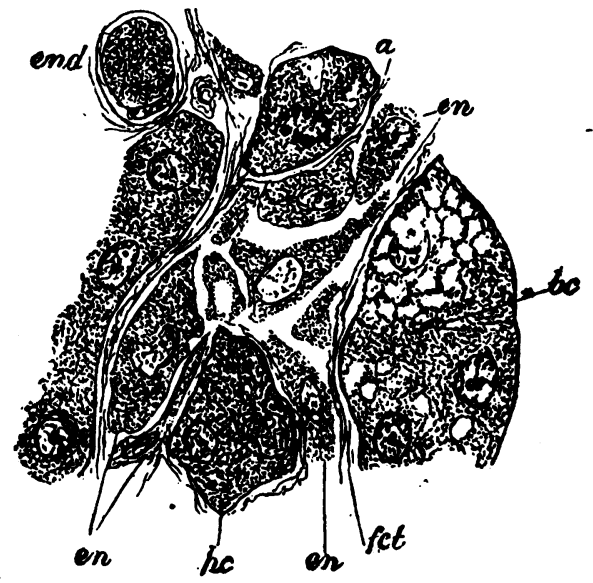

Fig. 3.-From the yellow area; $a$, liver cell with nucleus undergoing division; $h c$, hepatic cells; $b c$, enlarged bile capillary ; $f c t$, fibrillar eonnective tissue of blood capillary wall; end, endocyte in an endothelial

Goodhart's view that the apparently greater prevalence of biliary ducts is due to the contraction of the hepatic tissue and the resulting crowding together of the ducts in the interlobular canals, is, we think, correct; but it does not account for the larger than average size of the'cells constituting these ducts nor for the presence of large-celled ducts within the lobular areas. It seems to us that the true explanation is as follows: In the normal condition the ducts of the interlobular canals are lined with epithelial cells of various sizes, and of shapes from columnar and cubical to the flat or scale form. The scale form is chiefly found in those finer ducts which are on the point of entering the lobules. The eells of all these ducts in acute atrophy increase in size, and this is due to the same condition which is responsible for the large size of the endothelial cells in the adjacent tissues. What this condition is is doubtful, although we believe that on the degeneration and death of the liver cells the resulting proteids and other compounds set free are absorbed by the surviving cells. Indeed, at times one can see in the endothelial cells pigmented granules which could only have come from the fiver cells. The increase in the amount of the protoplasm of the cells of the ducts, its finely granular, and, to a certain extent, its eosinophilous character, are evidences that these cells are degenerating also or that the cells are absorbing the remains of degenerated or broken-down cells. The absorption of chromatin is shown by the large lobulated nucleus and its deeply staining contents in a few of these cells (Fig. 8, $a$ and $b)$. It is of course inside the margins of the original lobules that one can at times detect the transformation of the flat lining cells into the large cubical cells. Both the cell body and the nucleus of each of these are rich in chromatin, and this is so manifestly over-abundant at times that one is forced to the conclusion that it is derived through diffusion and ab- 
sorption from the debris of destroyed liver cells. It is in such cells that one should expect to see cell division. Why it is sbsent when the cell is at least so nourished as to increase in size is puzzling. Sometimes these cells surpass the liver cells in size and then the nuclei are usually lobulated, as in the lymphoid cells of the spleen, bone medulla, or as in old leucocytes. The condition which underlies these nuclear phenomena is the abundance of chromatin, for which the ymphoid cells act as storehouses.

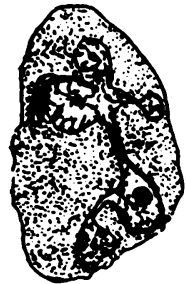

a.

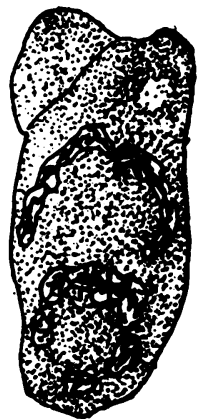

b.
Fig. 8. $-a$ and $b$ represent cells of the bile ducts in the red area, with lobulated nuclei and enlarged cell body. $\times 1,000$.

As already remarked, the condition known as red atrophy is very marked in extent. Before describing the structure of the tissue exemplifying it we will treat of the part manifesting the yellow atrophy first, since, on the ground that the red is a later stage of the yellow condition, the nature of the changes in the former will thereby be rendered clearer.

The hepatic parenchyma remains only immediately under the capsule. The average appearance of the lobules is represented in Fig. 1. The number of liver cells left in a lobule varies, it sometimes being a little less than normal, while, again, it may be sufficient only to constitute a small group. Where, however, the number and condition of the cells appear normal, the vascular channels between them are enlarged in calibre, and even at the margin of such lobules hepatic cylinders may be separated by large areas of connective tissue, endothelial cells, and leucocytes. The first change from the normal is manifested by the coarse granulation, or the fatty vacuolation, which appears in that part of the cell next the blood capillary. The enlargement of the bile capillary is another feature of this change, although it may be secondary to changes in the immediately adjacent cells, since it is probably due to obstruction of the bile capillaries by protoplasmic masses placed there by the cells themselves, in which these are also seen (Figs. 5 and 6).
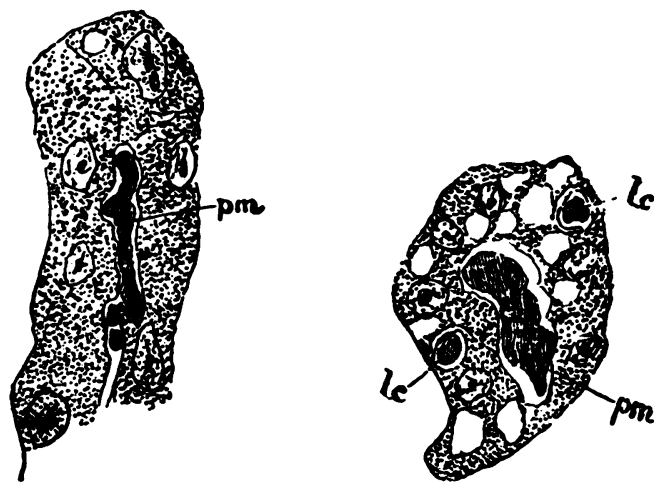

Figs. 5 and 6.-Portions of hepatic cylinders. $p m$, protoplasmic masses in the bile capillary; $l c$ leucocytes. In Fig. 6 the cells have undergone fatty vacuolation.

With further change the fat droplets become larger, the granulation much coarser, and the nucleus loses its structure and becomes more or less homogeneous. In cells which are coarsely granulated, but from which fat is absent, the membrane only of the nucleus may be detected, all else having vanished. In the enlarged cells in which fatty degeneration alone is prominent, the fat is collected in large droplets, separated from each other by protoplasmic septa, in which the granules are collected. In such the nucleus is of irregular shape, situated near the bile capillary, in the vicinity of which the bulk of the granular protoplasm is collected. The lumen of the bile capillary is then greatly enlarged (Fig. 7).

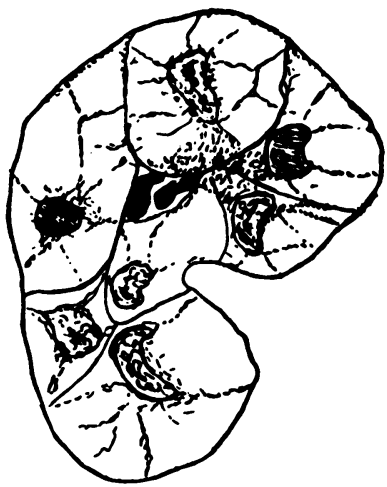

Fig. 7.-A group of liver cells greatly distended by vacuolation. The lumen of the bile capillary, which is enlarged, is occupied by protoplasmic masses. $\times 1,000$.

Examples of cell division amongst the nearly normal hepatic cells are sufficiently abundant to warrant the conclusion that, just as there is atrophy in one part, there is regeneration of the hepatic parenchyma in another. One might search for a long time in sections of the normal liver without finding as many cells dividing as we saw amongst the remaining cells of a few of our sections. It might be possible in this way to explain the cases of recovery from attacks of acute atrophy which have been reported.

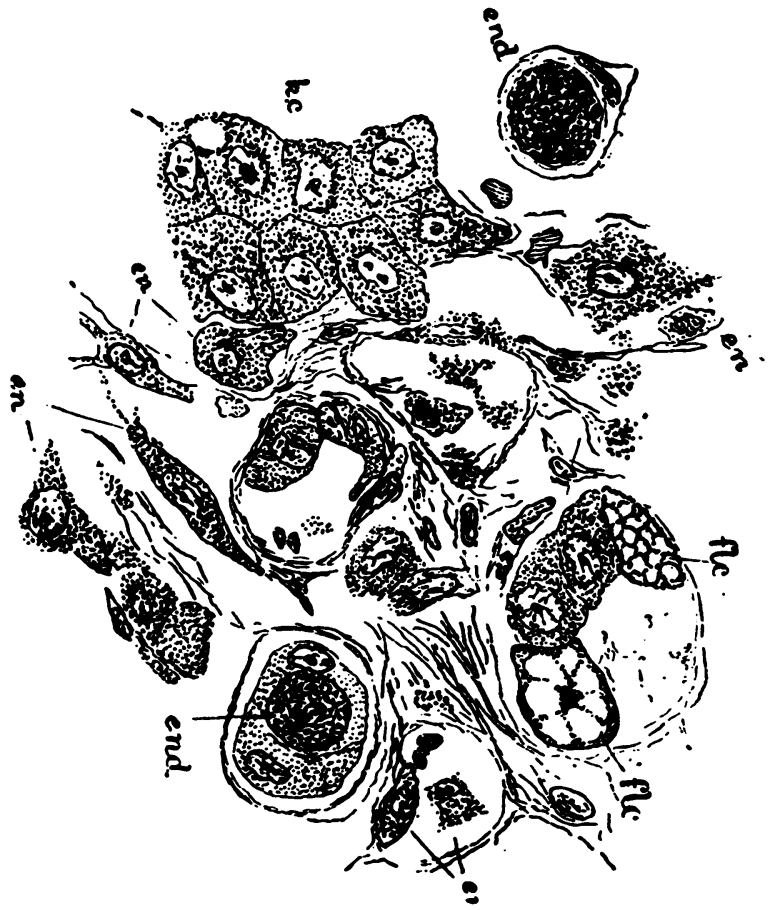

Dig. 4 -From the portion where atrophy is more advanced. 'It serves to show the difficulty of distinguishing in some cases between the hepatic and endothelial cells. $h c$, a part of a hepatic cylinder end, endocytes, the one to the right being in an hepatic cell; $A C$ the liver cells in a state of fatiy degeneration; en, endothelia cells; gr, granular remains of disintegrated hepatic cells. $\times 1,000$.

Returning now to the consideration of the more normal portions of the liver, we find that, in addition to enlargement of its calibre, the intralobular blood capillaries present other changes. In some cases these may be very slight, and may consist in such a disposition on the part of the endothelial cells to stain deeply with eosin; but in other cases, where the changes are further advanced concurrently with 
the degenerative ones in the hepatic cells, the endothelial cells are greatly enlarged in every direction, so that they sometimes appear to fill the lumen of the vessel. At the same time, their protoplasm becomes granular, and imbibes the eosin as readily as the neighbouring liver cells. The latter qualification, considered in connection with their sometimes coarsely granular protoplasm and elongated form, seems to be responsible for the view expressed by Winiwarter, that liver cells in acute atrophy are converted into connective tissue. The cells are sometimes so large that they rival the liver cells in size, and, indeed, in some cases are not distinguishable from them (Fig. 4).

At the same time that these changes are brought about in the endothelial cells, the connective tissue outside them and in the vascular wall becomes more coarsely fibrillated, and therefore apparently only increased in quantity. This fibrillar tissue stands out prominently where marked fatty degeneration is present, and here one can see between the fibrillæ the granular debris of the destroyed liver cells.

If, now, we pass to the areas where red atrophy is present, we find the condition just described markedly prominent. A liver cell is to be found here and there inflated with fat droplets, but the tissue is typically made up of fibrillæ running in every direction in a mesh form, and enclosing between them granules, some of them pigmented, and leucocytes, while the spaces in the meshwork are occupied by endothelial cells of various sizes, irregular shapes, and granular protoplasm. Had one no means of studying the development of these endothelial cells, they might be considered as persistent liver cells. Each cell may have more than one nucleus, which is usually irregular in shape, and the nuclear chromatin is deposited on the interior surface of the membrane. The cells contain sometimes refracting granules and pigment which, presumably, are derived from the degenerated liver cells. The few leucocytes present may be easily - overlooked in the abundance of endothelial elements.

In some parts of the section the spaces of the meshwork of fibrillar tissue are smaller than those represented in Fig.9,

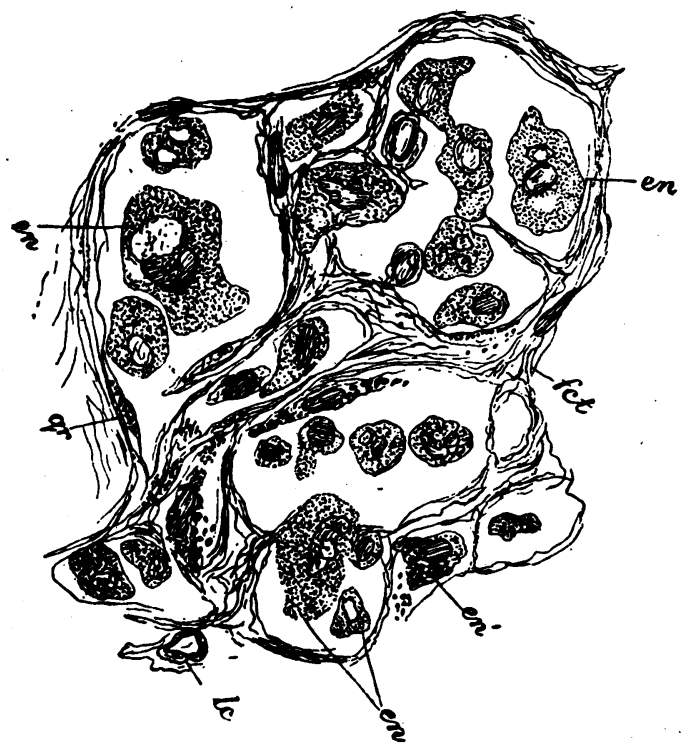

Fig. 9.-Portion of a section showing the structure of the lobules in the red area. $f c t$, the fibrillar connective tissue of the original walls of the intyalobular blood capillaries; $g r$, the granular remains of the disintegrated liver cells; $l c$, leucocytes; en, endothelial cells; $e n^{\prime}$, endothelial cells with pigment granules. $\times 1,000$.

and then the endothelial cells are compressed closely together, and appear as lymphoid elements.

The endothelial cells of some of the intralobular veins and venules are also enlarged, granular, and readily stained with eosin. They may lie free in the lumen of the vessel, and -they present identically the same appearance as the endothelial cells of the lobular areas, except that the latter are of greater size.

We can compare these endothelial cells only with those of the maternal capillaries of the placenta in the rabbit and cat. In the latter animal the enlarged eosinophilous endothelial cells point, on the one hand, to abnormal or excessive nutrition, and, on the other, to degeneration. This is probably true of the endothelial cells in acute atrophy, and this is supported by the fact that not one example of karyokinesis was observed in them.
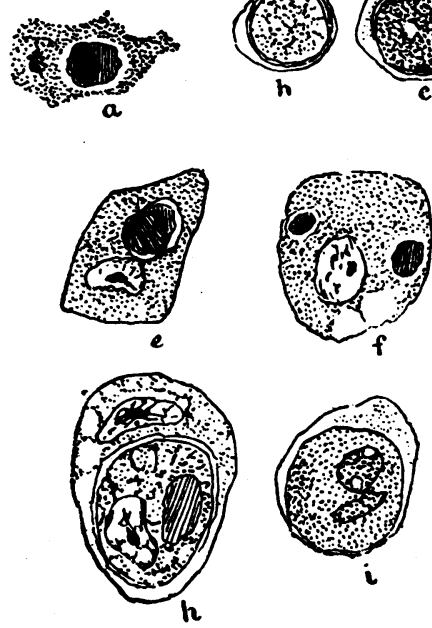

f

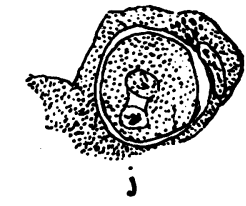

Fig. 10.-Examples of endocytes and other intracellular bodies. In $e$ leucocytes are enclosed within the cell ; in $f$ are protoplasmic masses; in the remaining ones are endocytes; $f$ and $h$ only are hepatic, the others representing endothelial cells. $\times 1,000$.

Some of the larger interlobular veins were filled with red blood corpuscles, but the latter were entirely absent from the other parts of the preparations, in spite of the greatest care taken to preserve their existence in the sections. In some way the lack of blood supply is connected with the atrophied condition, for nearly all the central venules of the lobules are obliterated, and, when present, possess very much thickened walls, while the more normal hepatic parenchyma is found directly under the capsule, where the normal circulation is freer than elsewhere.

We have now to describe structures which we believe have not been referred to before as occurring in this affection. As they are cellular elements in the interior of the hepatic or endothelial cells, they may be brought into the class of bodies termed endocytes-a name proposed by the junior author to designate conveniently, and without prejudice for any particular view as to their nature, the intracellular bodies of the affected epithelial cells in Paget's disease of the nipple, regarded by Darier and Wickham as psorosperms. These endocytes are absent from the areas of red atrophy, and are abundant in some parts of the margins of atrophying lobules. They are far oftener found in the enlarged endothelial cells than in the liver cells. They vary somewhat in their contents, but their shape is constant, being nearly spherical, and their protoplasm strongly eosinophilous. The latter character readily reveals them under the microscope. The protoplasm may be slightly and uniformly granular, or strings of granules may stretch through it, leaving the meshes filled with a homogeneous, easily-staining substance. Sometimes a nucleus can be readily seen, but it may be chromatolysed or so far degenerated that only the membrane can be seen. The endocyte is separated from the enclosing cell by a free zone usually, and the opposing surfaces of both are sharply outlined. The protoplasm of the enclosing "cell is sometimes reduced to a thin membrane covering the endocyte, and the nucleus is then pushed to one side, and appears crescent shaped, the concavity of the crescent being turned toward the endocyte.

We take these bodies to be leucocytes which have entered the hepatic or endothelial cells and thrive at the expense of the latter, but eventually share in the decay of the surrounding cells. We found leucocytes in both classes of cells, but 
the majority of those in the hepatic cells were more or less disintegrated, and it is probable that the protoplasmic masses in the interior of many of the liver cells are derived from them. Of course, with a limited quantity of tissue to study, and this in the most advanced stage of the affection, it was not possible to determine all the stages of the transition from the ordinary enclosed leucocyte to the endocyte.

We have considered the question whether these elements are parasitic or endogenously formed. We have rejected both hypotheses, because it seems to be a matter of the last resort to call them parasites, and because no definite examples of endogenous cell formation is known to occur in the animal kingdom; till such is found it is well to base explanations on well-grounded facts only.

Crystals of leucin and tyrosin were not observed. We used Loeffler's and Gram's methods for staining bacteria in our preparations, but could find no trace of bacilli or micrococci, and our experience in this matter agrees with that of Dreschfeld, who obtained negative results in preparations from the livers of two cases of acute atrophy.

\section{Graneral Remarks.}

There are some aspects in this case which may serve as a basis for consideration of some of the clinical features and symptoms of cases of acute atrophy in general. The facts obtained from the study of one case scarcely suffice, perhaps, for the purposes of generalisation, the less so since these facts do not coincide uniformly with those observed in other cases of acute atrophy. Many of these cases however have, we believe, been imperfectly studied as regards the structural changes in the organs affected, and this together with the rarity of the disease tends to postpone to the future the chances of obtaining the facts necessary for accurate conclusions. Theories and criticism are the great incentives to the collection of facts, and we are therefore encouraged to comment as we do now, on the ground that such a course will call for a fuller histological study of all the organs in future cases of acute atrophy, a performance which we regret the circumstances attending the necropsy in our case did not permit.

For the sake of convenience we will treat the points of our comment in the following order:

1. The nature and mode of production of the jaundice.

2. The etiology of the disease.

3. The cerebral and other symptoms.

1. Since catarrhal jaundice is of comparatively frequent occurrence, and cases of acute atrophy extremely rare, and, further, since obstruction of the bile ducts in any form has not been observed in the great majority of such cases, it seems superfluous to postulate the existence of catarrh in acute atrophy. Occupying this position, we do not think it necessary to hesitate between the hæmatogenous and hepatogenous origin of the jaundice. Even if we believed in the existence of the hæmatogenous variety, there would be no demand for the exercise of the belief in accounting for the jaundice, although on first thought it may appear that rejection of the catarrhal origin of the disease entailed a resort to such a theory. There are two ways in which resorption of the secreted bile may be brought about without the occurrence of obstruction due to catarrh, and these are: (1) the destruction of the finest bile capillaries between the liver cells at the periphery of the lobules, and (2) the plugging of all the remaining bile capillaries of the lobules. We maintain that our case illustrates both conditions. In the preparations the peripheral hepatic cells of the few remaining lobules have all disappeared, and it seems that this is the usual occurrence in acute atrophy. With the destruction of the liver cells all connection between the fine intralobular bile capillaries and the interlobular bile ducts is lost. It is true that some histologist $3^{i}$ have claimed an existence for the finest bile capillaries independent of the adjacent liver cells, and it might therefore be argued that destruction of the liver cells does not entail disappearance of the bile capillaries. The views as to the independent formation of bile capillaries have not been supported by the work of other observers, and they are in direct opposition to what we know of the liver from its functional and embryological aspects. With

Heidenhain and Peszke: See Hermañn's Handbuch der Physiologie, vol. v., pt. 1, p. 220 the peripheral bile capillaries destroyed, it is obvious that the secretion of the more centrally placed glandular cells must pass into the spaces previously occupied by the liver cells, and from them to the blood capillaries, whose endothelial cells are so seriously affected, as described above. Hence the jaundice. Now, in the remaining bile capillaries there is in our preparations more or less plugging by the protoplasmic masses, and this must assist, though in a minor degree, in the resorption of the formed bile constituents.

The question which follows the statement of these views is: How is the destruction of the periphery of the lobules brought about so that acute atrophy supervenes? The answer to this is the consideration of the second item of comment, the etiology of the disease.

2. The destruction of the liver cells and the fatty degeneration of renal tissue all point to the presence of a poisonous element as a cause of the disease. What this poisonous element is, whether due to pathogenic micro-organisms, or to abnormalities in the digestive processes or products in the intestine cannot be determined. The fact that bacteria have been observed in only a few cases does not decisively exclude their agency in the production of the trouble, although it warrants us in looking for some other ascertainable cause. All things considered, we incline to the view that the poisonous element is of the nature of a chemical compound, probably an abnormal albumin, resulting from deranged or putrefactive processes in the intestine, absorbed by capillary radicles of the portal vein, and carried to the liver, where it first meets tho hepatic cells at the periphery of the lobules, bringing about their destruction. The destruction once begun is continued in the remaining cells of the lobules more or less affected by the poison, and assisted by the resorbed secretions, and the impossibility of the liver cells in some cases throwing their secretions into the already over-distended bile capillaries.

That the digested products of impure food, when absorbed into the system, may produce acute atrophy, is shown by the cases described by West, ${ }^{2}$ of two children, one of which had the disease, while the other is reported to have manifested its symptoms before death. Both children were supposed to have eaten, a few days before their illness commenced, something thrown out of a herbalist's shop. Here bacterial organisms may be suspected as the prime cause of the trouble, as well as in those cases described as occurring simultaneously in the crews of vessels, or appearing successively in the same family or in the same household. In such the germs may influence the constitution of the proteids in the digestive tract, producing abnormal albumoses or like compounds, which, when absorbed by the portal system, affect the liver in the way described. We may explain cases in which the hæmorrhages are confined to the portal blood vessels by ascribing the changes in the vascular walls which permit the hæmorrhages, to the poisonous action of the absorbed elements first acting on the vessels removing them from the intestine.

Pregnancy is one of the most common conditions predisposing to acute atrophy, and it is possible that in this condition the constipation enhances the chances of unusual putrefactive processes occurring, and, on the other hand, weakens the defensive functions of the absorbing organs. It might be possible in future cases of acute atrophy, in which the condition of pregnancy is present, and in which the fœtus is jaundiced, to test, in a way, the view that the disintegration and death of the liver cells is brought about by a diffusible poisonous compound, for then the fœetal liver and tissues generally ought to show changes similar to those found in the maternal tissues. Some cases of acute atrophy cannot be ascribed to this agency, or rather another cause may appear to be more probable. Such are those brought about by the swallowing of a large quantity of concentrated alcohol, or by excessive indulgence in alcoholic beverages, and may be referred to a specific action of the alcohol on the liver cells less prominent and less certain than that produced by phosphorus.

3. An analysis of the cerebral symptoms in this disease can only be made on the ground of guess-work. Whether they are due to diminished nutrition of the brain tissue, as Traube believed, or to a toxic compound, is equally consistent with clinical facts. It may be pointed out, however, that in the $\frac{2 \text { crans. Path. Soc. of Lond., vol. xxxi, p. 116. }}{2 \text {. }}$ 
case of starvation in animals the brain does not diminish in weight, while the other organs are considerably reduced in volume and weight, and that even after very long periods of fasting in the human subject no unusual nervous symptoms may appear. Traube's view, therefore, appears less tenable, the more so as in some cases of acute atrophy the delirium and stupor came on early in the course of the disease, when a sufficient time had not elapsed for the brain to fall into the condition of inanition. In the great majority of the cases, moreover, the body appears well nourished.

If the nervous system constitutes the master tissue of the body, as starvation experiments show, it must have the power of rejecting as well as selecting the various compounds in its vascular fluids. One sees no reason why this power of rejection should not be as readily exercised against toxic elements as against an abundance of a single constituent in diet. The constant exposure to, and attack by, toxic compounds must, however, weaken this capacity until it does not excel that of any other organ of the body, and, when this point is reached, the action of the poison immediately becomes manifest in the cerebral symptoms. Thus we may explain the more or less sudden onset of uræmic coma and convulsions, the delirium, the convulsions, and the stupor of acute atrophy. This, of course, does not mean that the poison in both cases is the same. In acute atropliy the products of the disintegration of the liver cells may constitate the injurious element, and, if so, they are not likely to be similar to the products of a somewhat disordered metabolism retained in the system in other diseases.

The hæmorrhages are probably due to vascular changes, such as those described as occurring in the liver in our case. The observations of other authors on this point are very defective, and no generalisation can, therefore, be made, but we must accept this explanation, or turn to some such a one as that offered by Denys for the occurrence of purpura hæmorrhagica - the inordinate disintegration of blood plaques, and the consequent arteriole and capillary thrombosis.

\section{PERNICIOUS ANEMIA-SUCCESSFUL TREAT- MENT BY ARSENIC.}

By J. S. RISIEN RUSSELL, M.D., M.R.C.P., Assistant-Physician to the Metropolitan Hospital.

Since Dr. Byrom Bramwell ${ }^{1}$ published his three cases of recovery from this disease a number of cases have been recorded in which the administration of arsenic, as recommended by him, has been followed by successful results. In this country alone the number of cases thus treated successfully has been considerable. ${ }^{2}$ I think that this case should be added to the list :

J. T., aged 58, a man of average height, fairly nourished but intensely pale, first came under my care as an out-patient at the Metropolitan Hospital on January 14th, 1892, complaining of shortness of breath, swelling of his legs and face, an intense burning sensation in the rectum, and great weakness.

History. - He was unable to say how. long he had been getting pale, but had noticed his face becoming pufty for three months before he came to the hospital; it was always worse in the morning and subsided by the evening. The swelling of his legs was only of five days' duration, but during th at time they had become rapidiy worse. Shortness of breath was of some weeks' duration and had been steadily increasing so that at the time when he came under observation it was a very distressing feature of $h$ is illness. For some time his mouth and tongue had felt dry and rough, and his food did not taste natural; he suffered from nausea but there had been no actual vomiting. Three weeks before I saw him but had had an attack of diarrloe and to an intense sensation of burning in since then he had been subject an in the rectum, which was a source of great discomfort to him. This sensation was not constant, it only came on from time to time and was not in any way related to the act of deæcation. He also suffered from a scalding sensation along the urethra when he passed water, but there was no urethral discharge nor had there deen any. The patient had formerly enjoyed excellent health. He denied having had syphilis and no history of this affection could be No history of phthisis or malignant disease in his progenitors could be No history o

ascertained.

State on Examination.-The patient was evidently very ill. He was exceedingly pale, but there was in addition a distinct lemon-yellow tinge of the face. Pallor of the lips and mucous surfaces was marked. The conjunctivæ were yellowish in colour, and might easily have been mistaken for jaundice, as, indeed, had evidently been the case; for he had been under treatment for "congestion of the liver" for a month before he came to the hospital. His face was very puft, and the odema of his feet and legs was so great that he was no longer able to wear his boots; it was most marked about the ankle joints, but the skin pitted very distinctly over the tibiæ along the front of the legs. No subcutaneous or other hæmorrhages could be detected, and the most careful examination failed to discover any abnormal pigmentation such as

Blood.-I very much regret that I had not the means of estimating the
Busease. There were no glandular enlargements. ercentage of hæmoglobin before the treatment was commenced. The corpuscles ran badly into rouleaux; the red cells were greatly diminished in numbers, while the white cells were relatively increased. The red cells were variously altered in shape, many of them tailed, and others in process of disintegration. Large nucleated red cells were present.

Heart. - The cardiac action was regular, though rapid; no thrill could be felt over the præcordia, and the apex beat was not displaced. The cardiac dulness was not increased; no murmur was audible at the apex, but a systolic murmur accompanied the first sound over the pulmonary area. The pulse was rapid, but regular.

Lungs.-No abnormal physical signs could be detected in either lung: Bung8.- - o abropid, and the slightest exertion increased the dyspnca.

Abdominal Viscera. The abdominal organs presented no abnormal

Abdominal Viscera. - The abdominal organs presented no abnorma features. The liver and spleen were not enlarged, and no a

mass, glandular or otherwise, could be detected in the abdomen. Rectum.-The bowels acted regularly, but the patient was troubled
greatly by a burning sensation in the rectum. Nothing could be found on greatly by a burning sensation in the

Urinary Organs. - There was intense scalding on passing water, but no Urinary Organs.-There was intense scalding on passing water, but no
evidence of urethral discharge. Micturition was not frequent, and evidence of urethral discharge. Micturitiou was not frequent and the uringar.
sugar.

Treatment and Progress.

Such was the clinical history of the case, which appeared to me to justify but one diagnosis, namely, that of pernicious anæmia ; but it was of course necessary to exclude the possibility of intestinal worms being responsible for the anæmia, though it was highly improbable that those forms most likely to cause intestinal hæmorrhage would be found in $a$ man who had never been out of this country. Anthelmintic treatment was combined with the treatment of the anæmia, which consisted in the administration of arsenic and iron; but no intestinal worms or their products were evacuated. Four minims of liquor arsenicalis and 15 grains of the ammonio-citrate of iron were administered three times a day, and while the dose of the iron was only once increased throughout the time that the patient was under treatment, the arsenic was increased gradually until the patient was taking 12 minims three times a day, five weeks after the treatment was commenced. This amount of arsenic continued to be well borne until March 11th, 1893, when irritation of the eyes became so troublesome that it was discontinued, and the amount of iron increased to twenty grains three times a day. There were no other symptoms of arsenical poisoning, and this one improved rapidly under local treatment with boracic lotion, after the arsenic was discontinued. During the time that the patient had been taking arsenic there was steady and rapid abatement of his symptoms; but, when it was discontinued, he began to relapse slightly, so that, on March 25th, I ordered 4 minims of liquor arsenicalis in combination with the original dose of iron. The arsenic was subsequently increased to 6 minims, but it never became necessary to exceed this amount, and the treatment was discontinued altogether at the end of May. A fortnight after the treatment was commenced' there was distinct improvement, and by the end of a month he felt strong and better in every way; he could walk farther without becoming short of breath, and the œedema had subsided considerably. In fact, a week later, he could wear his usual boots with comfort. By the beginning of March he had lost much of this pallor, his appetite was greatly improved, the abnormal sensations of his tongue and mouth no longer troubled him, his food tasted natural; the burning and tenesmus of the rectum had ceased a fortnight before; there was only very slight œdema of the ankles. A week after the arsenic was first discontinued the patient complained of a creeping sensation in his skin all over, the face and scalp included. He had been subject to this a year or two before. and it had troubled him off and on since; it always commenced when he got warm in bed. By the end of April the patient was practically well, but treatment was continued a month longer. By the end of this time he looked and felt extremely well ; not one of the symptoms from which he formerly suffered persisted, and his cheeks were quite rosy.

\section{Subsequent History.}

He continued in excellent health until September, when he consulted me again owing to irritation and creeping sensations in his skin, which had returned, as had the scalding along the urethra during the act of micturition. I ordered 